\title{
A alegoria benjaminiana em No país das últimas coisas.
}

\section{Vivian Bernardes Margutti, UFMG}

Resumo: Este estudo propõe uma interpretação alegórica do romance No país das últimas coisas de Paul Auster, a partir de seu diálogo intertextual com Hawthorne e Bunyan, e da proposta de Walter Benjamin em Origem do drama barroco alemão, obra que apresenta uma perspectiva diferenciada tanto do conceito de barroco como da noção de alegoria.

Palavras-chave: alegoria; intertextualidade; poéticas da modernidade.

\section{Introdução}

Paul Auster é um escritor contemporâneo norte-americano de ascendência judaica. O reconhecimento de sua obra e sua popularidade têm sido notórios, pois sua escrita apresenta flexibilidade e complexidade, de forma a atingir tanto a esfera dos acadêmicos como a do leitor comum. A obra de Auster é extensa e variada. No âmbito da ficção, há dezesseis livros publicados. A intertextualidade é inerente à escrita de Auster, pois nela se percebem diálogos com autores como Kafka, Knut Hamsun, Poe, Hawthorne e Blanchot, entre outros. Há também uma repetição de temas, noções e núcleos narrativos que perpassam todos os seus livros, interligandoos. Apresenta-se, aí, a ideia de uma escrita intertextual que dialoga, também, consigo mesma.

A obra de Auster gerou vários trabalhos críticos publicados em revistas especializadas. Duas coletâneas de ensaios foram reunidas em livros - Bloom's modern critical views: Paul Auster e Beyond the red notebook: essays on Paul Auster. Há ainda o livro de Ilana Shiloh, professora de literatura americana na Universidade de Tel Aviv, e alguns textos disponíveis na rede virtual, como é o caso do ensaio filosófico de Gianluca Cuozzo, professor de filosofia da Universidade de Torino, traduzido para o português com o título de A equação mortal. Apesar da enorme gama de trabalhos críticos disponíveis sobre a obra de Auster, apenas alguns analisam o romance intitulado No país das últimas coisas, que será considerado aqui. Além disso, não há referência nestes ensaios críticos à alegoria, tema central do presente estudo. Por este motivo, procura-se apenas iniciar um conjunto de reflexões sobre as possíveis interpretações da literatura produzida por Auster pelo viés da alegoria.

A análise proposta neste artigo é proveniente da imbricação de textos sugerida na epígrafe do romance: "Não há muito tempo atrás, passando pelo portão dos sonhos, visitei aquela região da terra em que fica a famosa Cidade da Destruição". ${ }^{1}$ A frase é de Nathaniel Hawthorne no conto "A estrada de ferro celestial" (1843), que por sua vez é uma paródia baseada em $O$ peregrino (1678), a obra-prima de John Bunyan. Quando lido a partir das perspectivas de Hawthorne e Bunyan, o romance de Auster se transforma de forma iluminadora. $O$ peregrino é uma alegoria do século XVII, que retrata a caminhada espiritual de um cristão, desde sua conversão até sua morte, 
e sua consequente chegada à ansiada Cidade Celestial. Por ser uma paródia, "A estrada de ferro celestial" também utiliza o recurso da alegoria em sua reescrita irônica da obra de Bunyan. Assim, surge a seguinte pergunta: a linguagem utilizada em No país das últimas coisas pode ser considerada alegórica?

A palavra alegoria vem do grego e significa dizer uma coisa para significar outra (állos = outro; agorein = falar). A alegoria foi utilizada com frequência, sobretudo durante a Idade Média e o período Barroco. Posteriormente, os autores românticos passaram a considerá-la uma figura de linguagem inferior ao símbolo, evitando-a ao máximo. A revalorização da alegoria se dá na modernidade, em especial após os escritos de Walter Benjamin, que inicialmente traçam a identificação da alegoria no drama barroco alemão, e posteriormente em escritores modernos, como Baudelaire. $\mathrm{O}$ pensamento de Benjamin abre as portas para a possibilidade de configurações diversificadas da alegoria como recurso retórico na tradição literária.

Em sua tese de livre-docência intitulada Origem do drama barroco alemão, Benjamin destaca a Reforma Protestante e a Contra-reforma católica como marcos históricos, que quebram o paradigma de salvação prevalente até a Idade Média. A crença medieval de que todos aqueles que estivessem inseridos na comunidade cristã seriam salvos inscreveu a história no processo da salvação. Entretanto, após os movimentos mencionados acima, a história foi esvaziada de transcendência e de escatologia, pois a salvação se tornou um processo individual e incerto. A partir disso Benjamin observa que no período Barroco a vida humana se sujeita ao destino e ao efêmero, caminhando naturalmente para a fatalidade da morte, o mundo passa a ter uma aparência incompleta e fragmentada e a história se transforma em uma sequência de catástrofes, seguida da aniquilação final. ${ }^{2}$

Benjamin, então, afirma que a arte alegórica do período Barroco está em sintonia com o pensamento da época por ser uma linguagem que retrata tanto em sua forma como em seu conteúdo a ambiguidade de sentido, a incompletude, a morte e a decadência, tão presentes na percepção barroca.

Quando, com o drama barroco, a história penetra no palco, ela o faz enquanto escrita. A palavra história está gravada, com os caracteres da transitoriedade, no rosto da natureza. A fisionomia alegórica da natureza-história, posta no palco pelo drama, só está verdadeiramente presente como ruína. ${ }^{3}$

A linguagem do mundo histórico fragmentado sugerido por Benjamin é alegórica, pois agrupa os restos e as ruínas, criando assim um novo objeto. Este se apresenta ao leitor como um enigma, fazendo-se necessária, então, uma busca por decifração. O resultado é o resurgimento do objeto que fora esvaziado de sentido ao ser retirado de seu contexto inicial, mas que, ao ser deslocado para um contexto diferente, renasce com um novo significado.

A obra de John Bunyan, apesar de ser uma alegoria cristã que se encaixa mais nos moldes da Divina comédia, já apresenta características que podem ser identificadas, posteriormente, no gênero romance. O conto de Nathaniel Hawthorne, além de criticar a tradição da analogia através de suas caricaturas alegóricas, pode ser visto como a semente da alegoria moderna presente no romance de Auster, como será visto a seguir. 


\section{A Cidade da Destruição}

A cidade sem nome de Auster faz correspondência com a Cidade da Destruição através da utilização de uma linguagem alegórica que dialoga com a tradição literária e com a sociedade e a cultura contemporânea. A escrita de Auster segue um caminho diferente da retórica caricatural de Hawthorne, pois utiliza o desnudamento, a escassez e a falta para levantar questionamentos sociais e espirituais.

Anna Blume, a protagonista de No país das últimas coisas, escreve uma carta a um destinatário incerto, sobre suas aventuras e desventuras em uma cidade sem nome. Ao ler o romance, o leitor é levado a associar a cidade de Anna à Cidade da Destruição, nomeada na epígrafe. Em O peregrino, segundo as notas de estudo de Scott, a Cidade da Destruição simboliza "o presente mundo mau, que está condenado às chamas, ou à condição de pecadores apáticos, mergulhados em objetivos e prazeres seculares". ${ }^{4}$ Ela nada tem a ver com a Cidade Celestial, que, segundo a doutrina protestante, além de ser destino daqueles que se convertem a Cristo, é um lugar inconcebível pelo ser humano, devido à sua natureza divina. A Cidade Celestial é feita de ouro e pedras preciosas, em suas ruas circulam anjos, o Rio da Vida ali flui, e Deus, Ser Supremo e Bondoso, está assentado em Seu trono próximo a todos que vivem no local.

No romance não há referência ao peregrino de Bunyan ou ao de Hawthorne, e nem mesmo a qualquer lugar que se assemelhe à Cidade Celestial, meta de ambas as peregrinações mencionadas acima. Anna Blume, no entanto, faz um percurso diferente, pois deixa sua cidade natal para se aventurar na própria Cidade da Destruição, local a que poucos se arriscariam a ir, devido ao perigo que subjaz ali. Ao contrário de Cristão, sua busca não é espiritual, pois seus objetivos são, aparentemente, palpáveis: em primeiro lugar, encontrar seu irmão e, após o fracasso desta busca, sair daquela cidade.

Em contraste com a Cidade Celestial, os moradores da cidade sem nome de Auster não se lembram da existência de Deus, lutam de forma sofrida pela própria sobrevivência e não têm sequer a esperança de sair daquele lugar, vivendo com a constante e perturbadora sensação de aprisionamento. São pessoas solitárias que, na maior parte dos casos, vivem vagando pelas ruas. De forma antagônica, algumas estão em busca do próprio sustento, e outras, da própria morte. Há, no ar, uma espécie de selvageria, gerada pela situação de extrema escassez e necessidade em que se encontram. Como resultado, é nutrido um individualismo exacerbado, devido a estômagos famintos e corpos frágeis, expostos às mais inclementes manifestações climáticas.

$\mathrm{O}$ ato da escrita para Anna vem de uma vontade interna de deflagrar uma vivência insustentável. Este desejo pode ser associado à sensação de premência da escrita. Anna e Samuel, os personagens escritores, precisam divulgar aquilo que acontece na cidade sem nome. Através da escrita, eles podem materializar o não-dito, informar e alertar seus leitores sobre a realidade infernal daquela cidade. Eles não buscam a possibilidade de algum retorno financeiro, ou mesmo a garantia de que haverá leitores para seus textos.

Para sobreviver naquele local, Anna escolhe trabalhar como caçadora de objetos ${ }^{5}$, o que significa que ela passa o dia caminhando pelas ruas, empurrando um carrinho de compras que é, por medida de segurança, amarrado a ela com uma corrente chamada de cordão umbilical ${ }^{6}$. Anna percorre o asfalto em busca de objetos 
abandonados que possam ser reutilizados ou reciclados. Estes objetos são, posteriormente, vendidos aos Agentes de Ressurreição ${ }^{7}$.

A fome é uma presença constante naquele local. Segundo Anna, a fome é o que a faz seguir em frente, uma espécie de motor que a impulsiona a dar o próximo passo. Cada habitante da cidade lida com a fome de modo diferente: alguns vivem obcecados por comida, devorando tudo o que encontram pela frente, até mesmo arriscando suas vidas por uma migalha qualquer. Existem, também, aqueles que comem cada vez menos, procurando, com este ato, uma auto-suficiência insustentável, pois morrem de inanição. Anna está entre as pessoas que comem somente o suficiente, com o intuito de se acostumar com pouco, para que assim o desejo possa ser satisfeito mais facilmente: ${ }^{8}$

É assim que eu vivo, continuava sua carta. Eu não como muito. Apenas o suficiente para me manter passo a passo, e nada mais. Em alguns momentos, minha fraqueza é tão grande que sinto que o próximo passo jamais virá. Apesar dos lapsos, consigo manter-me em movimento. ${ }^{9}$

Como não há restaurantes na cidade e os recursos são escassos, algumas pessoas optam, ainda, por satisfazer sua fome através das palavras. O processo de degustação é semelhante ao da narrativa oral, já que pressupõe a necessidade de ouvintes e um narrador. Neste caso, a narração é feita por um dos participantes do grupo de cada vez, como em uma conversa. Aos poucos eles descrevem detalhadamente a aparência e o gosto de cada prato degustado, começando pela entrada até, finalmente, a sobremesa. Como eles criam uma situação puramente imaginária, devem seguir um protocolo rigoroso para que ela seja vivenciada de forma correspondente. Os participantes não podem gritar ou suspirar repentinamente e não é permitido rir ou chorar, pois tais atitudes os reconduziriam imediatamente para a fome que de fato sentem naquele momento.

Para obter resultados melhores, é necessário que sua mente se jogue nas palavras que saem da boca dos outros. Se essas palavras puderem consumi-lo, terá capacidade de esquecer sua fome atual e entrar naquilo que as pessoas chamam de "arena do nimbo reconfortante."10

Anna se refere a estas pessoas como fantasmas, que, através da língua dos fantasmas, entram na arena do nimbo reconfortante. As pessoas-fantasmas iniciam, assim, um processo de desaparecimento, no qual elas tendem a vagar com um sorriso esquisito no rosto e um olhar que não parece delas. É uma espécie de morte por inanição, que é adiada pelo sugestivo mundo das palavras, levando a pessoa a um alto grau de torpor mental e físico. No nível metalinguístico, a língua dos fantasmas se refere à linguagem ficcional, que transporta o leitor para um mundo imaginário. As pessoas-fantasmas corresponderiam aos leitores, que são seduzidos a acreditar no que as palavras dizem. A narração tem um tempo longo de duração, e os detalhes são minuciosos. Através deles, os leitores vivenciam a experiência do outro, em um tempo e espaço diferentes do seu.

Por fim, devido ao estado de debilidade no qual se encontram estes moradores, a chegada da morte é iminente no cotidiano da cidade. Portanto, há um grande movimento em prol da morte, como se ela fosse um bem de consumo, ou uma espécie de religião com ritual público. A morte se torna um dos mais íntimos desejos 
destas pessoas, e por isso surgem empresas que oferecem serviços como o extermínio fácil e sem dor proporcionado pelas Clínicas de Eutanásia ${ }^{11}$. O cliente pode escolher entre Viagem de Retorno, Jornada das Maravilhas e Cruzeiro do Prazer $^{12}$. Cada uma tem um preço e uma proposta diferente. Há, também, os Clubes do Assassinato $^{13}$, que cobram uma taxa de inscrição e, a partir de então, o participante está sujeito a ser morto a qualquer momento por um assassino designado, de forma rápida e violenta.

Assim segue a narrativa, no ritmo da escassez, do imprevisível e do inesperado. A cidade tem regras próprias que tendem a causar surpresa em quem está acostumado com os "esplendores burgueses". ${ }^{14}$ Há falta de abrigo e de alimento, a economia é voltada para a reciclagem de objetos descartados, pessoas vagam pelas ruas. A cidade de Anna é assombrosa, há sofrimento, medo, angústia, pessoas se atacam e roubam. Na cidade das últimas coisas algumas palavras são até mesmo esquecidas. Entretanto, há um tipo de saciedade que pode ser vivida, em um nível ilusório de histórias inventadas.

É uma incógnita o fato de haver tantos habitantes nesse local, já que muitas pessoas morrem diariamente e os bebês se recusam a nascer. A impressão que se tem é de que a própria cidade está se consumindo. É impossível compreender exatamente como a urbe sobrevive, pois nada se constrói. Pelo contrário, prédios e ruas simplesmente desaparecem. Este estado de incertezas e possibilidades imprevisíveis leva os habitantes a desenvolver táticas para sobreviver.

Pouco a pouco, a cidade lhe rouba a certeza. Não pode haver nunca um caminho fixo e você pode sobreviver somente se nada lhe for necessário. Sem aviso, você deve ser capaz de mudar, de deixar o que está fazendo, de inverter. No final, não há nada que não importe. Em consequência, você deve aprender a ler sinais. Quando os olhos vacilarem, o nariz por vezes servirá. ${ }^{15}$

É importante a indicação de que há algum sentido por trás do caos aparente, podendo ser eventualmente captado através de uma leitura interpretativa. O romance de Auster expressa um olhar alegórico que corresponde ao descrito por Benjamin, tanto em termos de forma como em termos de conteúdo. Assim, quando Anna dá destaque à necessidade de aprender a ler os sinais, ela sugere não só a construção alegórica do texto a partir daquilo que é fragmentário e disperso, mas indica, também, a indispensável tarefa do leitor de dar novo sentido às palavras e às imagens descritas naquela narrativa.

A partir da longa carta apressadamente escrita à mão por Anna Blume, surge diante dos olhos do leitor uma cidade tenebrosa que pode ser comparada ao próprio inferno, mas curiosamente, também a inúmeras cidades dos séculos XX e XXI. Sugere-se que Anna se encontra em um espaço que, apesar de parecer um futuro distante, de fato faz referência a questões ligadas ao presente imediato. Weinstein ${ }^{16}$ afirma que certas figuras alegóricas demonstram um novo conceito de realismo, segundo o qual aquilo que parece remoto está perigosamente próximo daquilo que, de fato, é vivido. Seria uma espécie de provável futuro próximo para o mundo atual. Neste, já há pessoas que circulam com carrinhos à procura de lixo reciclável, da mesma forma que também havia em 1987, época em que Auster publicou o romance. A imagem de Anna catando objetos descartados, quebrados, amassados e sujos, se assemelha à imagem do trabalho do alegorista. Segundo Benjamin, o alegorista se debruça diante das ruínas da história, procurando transformá-las e dar-lhes novo 
sentido. ${ }^{17}$ Anna percorre as ruas da cidade à caça de objetos que possam ser utilizados de uma nova forma e com um novo significado. Anna pode ser percebida como metáfora do escritor-alegorista. A partir de sua escrita os cacos da história criam um mundo alegórico, onde o excesso se une à escassez, gerando imagens enigmáticas que procuram levar a insustentabilidade da sociedade moderna a suas últimas consequências.

Ruas cheias de lixo, que é catado e posteriormente reutilizado, remetem a questões de cunho social. Como as pessoas daquela cidade convivem com tão excessiva e talvez desnecessária produção de lixo? Como pode algo que é rejeitado por uma pessoa ser útil e possuir valor para outras pessoas? Qual a relação entre a cidade de Anna e o mundo contemporâneo? Nessa cidade não se constatam explicitamente a produção e o consumo de bens. Há apenas o lixo pelas ruas, apenas as ruínas reutilizáveis ou não de um sistema falido.

A figura de Anna empurrando um carrinho de compras remete imediatamente à sociedade de consumo. Um carrinho de compras que precisa ser amarrado a ela com um fio denominado cordão umbilical por uma questão de segurança, pois nem todos possuem tais carrinhos para reunir seus achados. Literalmente, o cordão umbilical é constituído de material orgânico e transporta sangue rico em oxigênio para o feto, algo essencial para a vida e o desenvolvimento do embrião. Ironicamente, o objeto utilizado para ajuntar e recolher a reminiscência e os restos reaproveitáveis, se torna algo de extremo valor para a sobrevivência. Sem aquele carrinho, Anna não tem como trabalhar, sem seu trabalho, ela não tem como se alimentar e sobreviver naquele local. Observa-se a dependência da vida humana em relação a objetos materiais consumíveis.

O carrinho de compras de Anna coloca em xeque o sistema capitalista da produção e do consumo sem fim. O excesso de lixo e a necessidade de reciclagem na sociedade contemporânea são questões de alcance mundial, que trazem à tona a desigualdade social e uma grande ameaça ao meio ambiente. No romance, o papel dos Agentes de ressurreição, aqueles que revendem as pérolas do lixo, não deixa de ser irônico, pois remete à esperança. Ali, onde só há lixo e destruição, há também a possibilidade de transformação e de renascimento. Esta mesma relação pode ser apontada em nível espiritual, quando os principais personagens do romance, apesar de acabados, famintos e depauperados, encontram uma sobrevida transformadora.

Sem clemência alguma, o mercado de oferta e demanda na cidade das últimas coisas se baseia no capital e na propaganda, no engano e nos desejos, como é o caso das empresas especializadas no extermínio de indivíduos. O governo é autoritário e tendencioso, privilegiando apenas alguns. A cidade se auto-consome, mas também se auto-renova, através da combustão de corpos e matéria orgânica, com a consequente geração de energia. Alguns habitantes da cidade trabalham no mercado de compra, venda e troca, outros trabalham para os órgãos governamentais, alguns roubam, outros enganam. A maior parte das pessoas da cidade está preocupada somente com as próprias mazelas. Anna está entre aqueles que vivem honestamente, ela sobrevive do dinheiro gerado pelo seu trabalho como caçadora de objetos. $\mathrm{O}$ individualismo de Anna não é tão forte que a impeça de perceber e ajudar o outro. Paradoxalmente, nesta cidade cabe tanto a secularidade do mundo mau como a redenção.

A circularidade do lixo que se renova e do ser humano que se transforma está presente também na intensa busca por preenchimento em diversos níveis da história narrada. Um exemplo é o caso da fome, que perpassa a narrativa como uma 
dificuldade diária dos personagens. A sensação de fome aponta para um vazio no interior de estômagos carentes de alimento. De forma semelhante, as pessoas, em sua subjetividade individual, seguem famintas de sentido. Elas procuram alguma forma de completar a distância que as separa do mundo objetivo e da transcendência, sendo este o sentido figurado da fome. A premência da escrita também pode ser associada à metáfora da fome. No sentido figurado essa necessidade de expressão vincula-se à fome de significado. É como se, através do texto produzido, o escritor pudesse alcançar a sensação de saciedade e completude. Entretanto, o romance de Auster nos mostra que essa sensação é puramente imaginária e ilusória.

Além disso, como discutido anteriormente, a ilusão criada pela linguagem gera uma espécie de apego naquele que escreve ou lê. Cabe relembrar as três formas de lidar com a fome, descritas por Anna: a voracidade, a abstinência, ou o comer apenas o suficiente. Através delas, pode-se dizer que o leitor ou o escritor faminto por palavras também passa por experiências semelhantes. Há a tendência, como é o caso de Samuel Farr, de transformar o apego a esta ilusão gerada pela linguagem em uma espécie de vício, algo obsessivo e exaustivo em si mesmo. Samuel passa a viver para a redação de seu livro, como um prisioneiro de sua própria escolha. Anna, por sua vez, procura usar as palavras seguindo o caminho do meramente suficiente. Anna sabe da ilusão gerada pela linguagem e não permite ser avassalada por ela. De qualquer forma, a experiência da linguagem gera o espaço de possíveis e momentâneas utopias.

A morte é tratada de forma semelhante, pois a maior parte dos habitantes da cidade parece não encontrar qualquer tipo de preenchimento que satisfaça, sendo assim impulsionados a buscar a própria morte. Além da referência à debilidade humana e ao fim da vida, esta busca também revela uma esperança que nasce das trevas, a esperança de que a morte será uma viagem menos sofrida do que a própria vida.

A partir desta leitura, pode-se relacionar a noção moderna de ironia com o sentimento de melancolia sugerido por Benjamin. ${ }^{18}$ Segundo os estudos desse autor, tal sentimento se tornou explícito com a Reforma e a crença na graça, que tirou do homem a possibilidade de se justificar diante de Deus através das obras. Benjamin também descreve o alegorista como um melancólico, ao se debruçar perante os cacos da história, procurando dar algum sentido àquele quebra-cabeça. Observa-se que o alegorista contemporâneo deixa transparecer, através de seu tom irônico, o sentimento de melancolia.

A ficção e a realidade se misturam em um mundo alegórico de excessos, de maneira um pouco semelhante à estética do período barroco. A cidade de Auster lembra uma escultura barroca com suas inúmeras caveiras que escancaram a iminência do fim da matéria. Este cenário se identifica com o mundo histórico descrito por Benjamin que, de forma semelhante ao período barroco, na contemporaneidade se encontra em estilhaços. As incertezas denotam uma percepção da história esvaziada de qualquer tipo de transcendência e de escatologia, sendo então uma sequência de catástrofes, seguida da aniquilação final. Uma vida sujeita ao destino e ao efêmero. A alegoria contemporânea retrata em sua forma e em seu conteúdo a ambiguidade de sentido, a incompletude, a morte e a decadência. Entretanto, mesmo nas ruínas, há a ínfima possibilidade de redenção e transformação, gerando o movimento cíclico da busca de sentido do alegorista. 
Abstract: This study suggests an allegoric interpretation of the novel In the Country of Last Things by Paul Auster, considering its intertextual dialogue with Hawthorne, Bunyan, and Walter Benjamin's proposal in The Origin of German tragic Drama, a work that presents a differentiated perspective not only on the concept of baroque but also on the notion of allegory.

Keywords: allegory; intertextuality; poetics of modernity.

\section{Referências Bibliográficas}

AUSTER, Paul. In the country of last things. Nova York: Penguin Books, 1988. $\left(1^{\mathrm{a}}\right.$ publicação pela Editora Viking Penguin em 1987)

BUNYAN, John; OWENS, W. R. The pilgrim's progress. Oxford: Oxford University Press, 2003.

BENJAMIN, Walter. Origem do drama barroco alemão. Trad. Sérgio Paulo Rouanet. São Paulo: Editora Brasiliense, 1984.

HAWTORNE, Nathaniel. The Celestial Railroad. 1843. Disponível em <http://www.walkworthy.net>. Acesso em maio de 2009.

MARGUTTI, Vivian. Narrativas alegóricas: do Barroco à contemporaneidade. In: Revista Em Tese, vol. 18, n. 1. Pós-Lit/FALE: 2012. Disponível em: <http://www.letras.ufmg.br/poslit/08_publicacoes_pgs/Em\%20Tese\%2018/18->. Acesso em agosto de 2012.

SCOTT, Thomas. Notas de estudo. In: BUNYAN, John. O peregrino: com notas de estudo e ilustrações. Trad. Hope Gordon Silva. São Paulo: Editora Fiel, 2005.

WEINSTEIN, Cindy. The literature of labor and the labors of literature: allegory in nineteenth-century American fiction. EUA: Cambridge University Press, 1995.

\section{Notas}

1 "Not a great while ago, passing through the gate of dreams, I visited that region of the earth in which lies the famous City of Destruction" (Hawthorne, citado na epígrafe de In the country of last things).

${ }^{2}$ MARGUTTI. Narrativas alegóricas, p. 3 e 4.

${ }^{3}$ BENJAMIN. Origem do drama barroco alemão, p.199.

${ }^{4}$ SCOTT. Notas de estudo, p. 20-21.

5 “object hunter."(AUSTER. In the country of last things, p. 32 e 33).

6 "umbilical cord" (AUSTER. In the country of last things, p. 33).

7 "Resurrection Agents" (AUSTER. In the country of last things, p. 33).

${ }^{8}$ AUSTER. In the country of last things, p. 2. 
9 “'This is how I live, her letter continued. I don't eat much. Just enough to keep me going from step to step, and no more. At times my weakness is so great, I feel the next step will never come. But I manage. In spite of the lapses, I keep myself going." (AUSTER. In the country of last things, p. 2).

10 "For best results, you must allow your mind to leap into the words coming from the mouths of others. If the words can consume you, you will be able to forget your present hunger and enter what people call the arena of the sustaining nimbus." (AUSTER. In the country of last things, p. 9 e 10).

11 "Euthanasia Clinics" (AUSTER. In the country of last things, p. 14).

12 "Return Voyage, Journey of Marvel, Pleasure Cruise." (AUSTER. In the country of last things, p. 14).

13 "Assassination Clubs" (AUSTER. In the country of last things, p. 14).

${ }_{14}$ Texto original: bourgeois splendors. (AUSTER. In the country of last things, p. 135.)

15 "Bit by bit, the city robs you of certainty. There can never be any fixed path, and you can survive only if nothing is necessary to you. Without warning, you must be able to change, to drop what you are doing, to reverse. In the end, there is nothing that is not the case. As a consequence, you must learn how to read signs. When the eyes falter, the nose will sometimes serve" (AUSTER. In the country of last things, p.6). Grifo meu.

${ }^{16}$ WEINSTEIN. The literature of labor and the labors of literature, p. 47.

${ }^{17}$ BENJAMIN. Origem do drama barroco alemão, p. 199 a 204.

${ }^{18}$ BENJAMIN. Origem do drama barroco alemão, p. 161 a 181 e p. 207. 